\title{
A comparative study of intrathecal $0.5 \%$ hyperbaric bupivacaine with dexmedetomidine and $0.5 \%$ hyperbaric bupivacaine with fentanyl for lower abdominal surgeries
}

\author{
G Suresh ${ }^{1}$, CGS Prasad ${ }^{2 *}$ \\ Resident $^{1}$, Associate Professor ${ }^{2}$, ESIC Medical College PGIMSR, Rajajinagar, Bangalore, India. \\ Corresponding author: prasad_cgs@yahoo.co.in
}

\begin{abstract}
Background
Adjuvants are added to improve the quality, to accelerate the onset of action and to overcome the problems of spinal anaesthesia. Depending on the purpose various adjuvants like morphine, fentanyl, clonidine, midazolam and dexmedetomidine are added. Adjuvants are administered by various routes like epidural, intrathecal and intravenous.
\end{abstract}

\begin{abstract}
Materials and methods
Following detailed pre-anesthetic check-up, patients were randomised into 2 groups in a sealed envelope, Group D received $2.5 \mathrm{ml}$ of $0.5 \%$ hyperbaric bupivacaine with $5 \mu \mathrm{g}$ dexmedetomidine and Group F received $2.5 \mathrm{ml}$ of $0.5 \%$ hyperbaric bupivacaine with $25 \mu \mathrm{g}$ fentanyl. Subarachnoid block was given between $\mathrm{L}_{3}-\mathrm{L}_{4}$ space with $25 \mathrm{G}$ Quincke spinal needle under aseptic precautions after free and clear flow of CSF in sitting posture. Onset of action, level of blockade, sedation score, duration of analgesia, adverse effects and hemodynamics were monitored. The first rescue analgesia was given when Visual Analogue Scale (VAS) was $>4$.

Results

In our study dexmedetomidine provided better sensory block, motor block and longer duration of analgesia. The highest sensory level achievedby group D 6(4-8) and in group F was 8(6$10)(p<0.005)$, time of two segment regression in group D110.33 \pm 11.544 min and group $F$ $81.50 \pm 15.6 \mathrm{~min}(\mathrm{p}<0.001)$, time of regression to $\mathrm{S}_{1}$ segment group D453.67 \pm 23.265 and group F $180.70 \pm 18.235(\mathrm{p}<0.001)$, motor blockade was in group D $407.53 \pm 18.913$ and in group F $149.37 \pm 12.497(\mathrm{p}<0.001)$ and time to rescue analgesia group D $231.93 \pm 17.836$ and group F $160.13 \pm 15.518 \mathrm{~min}(\mathrm{p}<0.001)$. The haemodynamic stability, sedation and side effects were similar in both the groups ( $\mathrm{p}>0.05)$.
\end{abstract}

\section{Conclusion}

We conclude that dexmedetomidine may be used as an alternate to fentanyl for intrathecal use and it may find a place forregular use in clinical practice.

Keywords: spinal anaesthesia, adjuvants, dexmedetomidine, fentanyl

\section{Introduction}

Spinal anaesthesia using local anaesthesia is associated with relatively short duration of action and thus early analgesic intervention is needed in post-operative period. ${ }^{1}$ Adjuvants are added to improve the quality, to accelerate the onset of action and to overcome the problems of spinal anaesthesia. Depending on the purpose various adjuvants like morphine, fentanyl, clonidine, midazolam and dexmedetomidine are added. Adjuvants are administered by various routes like epidural, intrathecal and intravenous. ${ }^{2 \cdot 3}$
Opioids are the most commonly used intrathecal adjuvants. Fentanyl being a lipophilic drug,

addition of a small dose to spinal anaesthesia can produce more rapid onset and better quality of surgical block and lead to more rapid recovery of motor function and allow for earlier discharge after surgery. ${ }^{4}$

Alpha 2 adrenergic receptor agonists like clonidine and dexmedetomidine have been the focus of interest for their sedative, analgesic, peri-operative sympatholytic and haemodynamic stabilizing properties. Dexmedetomidine is a new highly selective drug in this group. It has 
been approved by food and drugs administration for short term sedation for mechanically ventilated ICU patients. No neurological defects have been reported till date in both human and animal studies during intrathecal or epidural use. Clonidine has been studied extensively than dexmedetomidine. ${ }^{1,5}$

This study is intended to compare intrathecal $0.5 \%$ hyperbaric bupivacaine with dexmedetomidine and $0.5 \%$ hyperbaric bupivacaine with fentanyl for lower abdominal surgeries.

\section{Materials and Methods}

A prospective randomized controlled study was conducted from January 2012 to December 2012 after obtaining the approval of Institutional Ethical Committee at ESIC-Medical College PGIMSR, Rajajinagar, Bangalore. Data was collected from patients posted for lower abdominal surgeries in Department of Anaesthesiology, Pain and Critical Care. 60 patients were enrolled in this study, 30 in each group with below mentioned inclusion and exclusion criteria.

\section{Inclusion criteria:}

1. American Society of Anaesthesiologists Grade 1 and 2 patients.

2. Age 20-60 years of either gender.

3. Patients undergoing lower abdominal surgeries.

4. Patients free from cardiac and respiratory dysfunction.

\section{Exclusion criteria:}

1. American Society of Anaesthesiologists Grade 3 and 4 patients.

2. Patients with known contraindications for spinal anaesthesia.

3. Patients with haemodynamic instability.

4. Patient on antihypertensive and antidepressants.

\section{Method of collection of data:}

Pre - anaesthetic evaluation was done on the day prior to surgery. A detailed history was noted and a complete general and systemic examination was done. On the day of surgery, after confirming the fasting status the patient was shifted to the operating room. The anaesthesia machine, oxygen delivery system was checked. Airways, crash cart and all resuscitation equipment and drugs were kept ready. The patient was connected to monitors which included 5lead ECG, NIBP, $\mathrm{SpO}_{2}, \mathrm{HR}$ and RR. The baseline readings were noted. Intravenous access secured with $18 \mathrm{G}$ cannula and preloaded with $500 \mathrm{ml}$ of lactated Ringer's solution.

The patients were randomly assigned into 2 groups, Group F and Group D in a sealed envelope. Group F: received $2.5 \mathrm{ml}$ of $0.5 \%$ hyperbaric bupivacaine with $0.5 \mathrm{ml}$ of $25 \mathrm{mcg}$ fentanyl, total of $3 \mathrm{ml}$ and Group D: received $2.5 \mathrm{ml}$ of $0.5 \%$ hyperbaric bupivacaine with $0.5 \mathrm{ml}$ of $5 \mathrm{mcg}$ dexmedetomidine, total of $3 \mathrm{ml}$. The patient and observing anaesthesiologist were blinded to the drug group. Under strict aseptic precautions, spinal anaesthesia was carried out in sitting position. The time of injection $(0 \mathrm{~min})$ was noted and patient placed in supine position. After establishing adequate sensory and motor blockade, patient's bladder was catheterised and surgeons were asked to proceed with the surgery.

Vital signs like heart rate (HR), blood pressure $(\mathrm{BP})$, saturation $\left(\mathrm{SPO}_{2}\right)$, and respiratory rate (RR) were noted every 5 minutes for first hour then every 10 minutes for next hour and later every 15 minutes thereon. Onset of sensory block defined as the time interval between administrations of the drug to the loss of pinprick sensation at the site of surgical incision. Level of maximal sensory blockade defined as the highest dermatomal level of sensory blockade achieved. Time taken for regression of 2 segments from maximal sensory blockade and time taken for regression to $S_{1}$ sacral segments from maximal sensory blockade was noted. Motor block was assessed by using Bromage scale (Scale 1). The onset of motor blockade is defined as the time interval between administration of the drug to the inability to raise the extended legs, flex knees, ankle or move toes. Duration of motor blockade is taken when it regressed to Bromage 0.Sedation score was assessed by using Ramsay Sedation Score every 15 minutes after subarachnoid block till the end of procedure(Scale 2). Side effects during the entire procedure were noted and promptly treated. Hypotension defined as fall of systolic BP by $30 \%$ from basal recording was treated with mephentermine $6 \mathrm{mg}$ i.v. in incremental doses. Bradycardia defined as $\mathrm{HR}<$ 50 beats / min was treated with atropine $0.6 \mathrm{mg}$ i.v. Nausea and vomiting was treated with on 
dansetr on $4 \mathrm{mg}$ i.v. After the surgery, patients were monitored in the PACU for vitals like HR, $\mathrm{BP}, \mathrm{RR}$ and $\mathrm{SpO}_{2}$ every 15 minutes. The VAS score was used to assess pain. Time of rescue analgesia is defined as the time from sensory block to the time when patient complains of pain or VAS score of $>3$ (Scale 3). Injection tramadol $50 \mathrm{mg}$ i.v. was given as rescue analgesia. Once patients recovered from the sensory and motor blockade, they were shifted to postoperative ward.

\section{Scales}

I. Modified Bromage Scale (1978) is used to assess motor power:

$0=$ Free movement of legs, feet with ability to raise extended legs.

$1=$ Inability to raise extended legs, but able to move knees \& feet.

$2=$ Inability to raise extended legs or move knee. Able to move feet.

$3=$ Inability to raise extended legs, flex knees, ankle or move toes

\section{Ramsay sedation score}

\section{Score Responsiveness}

1. Patient is anxious and agitated or restless or both

2. Patient is co-operative, oriented and tranquil

3. Patients respond to commands only

4. Patient exhibits brisk response to light glabellar tap or loud auditory stimulus

5. Patient exhibits a sluggish response to light glabellar tap or loud auditory stimulus

6. Patient exhibits no response.

\section{VAS scale for pain assessment}
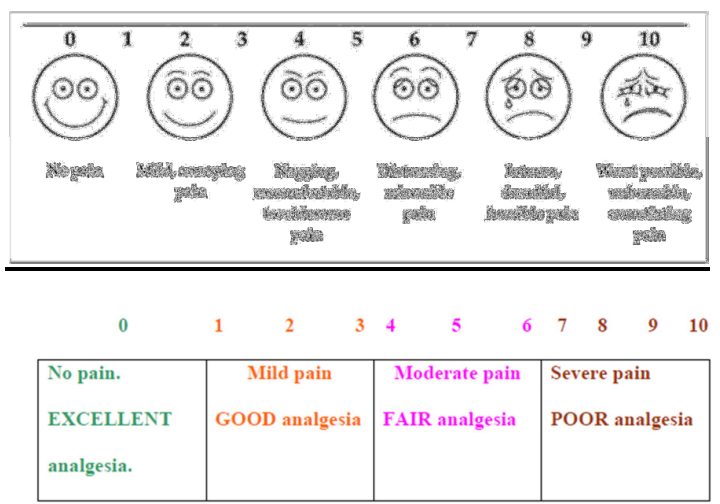

\section{Statistical analysis}

In the present study to calculate the sample size, with $80 \%$ power $(\beta$ error $=20 \%), 95 \%$ confidence $(\alpha$ error $=5 \%)$ and to minimum detectable difference between the groups as 15 min, required a minimum of 28 subjects. Data was analysed using Statistical Package for Social Science SPSS V18 software. p-value< 0.05 was considered for statistical significance. Descriptive statistics of time for highest sensory level, blood pressure, respiratory rate, heart rate were analysed and presented with mean and standard deviation. Independent t test was used to compare the average time for highest sensory level, blood pressure, respiratory rate, heart rate between the groups at different time. Chi-square test was used to compare proportion of complications between the groups. Continuous covariates were compared using analysis of variance (ANOVA).

\section{Results}

The demographic parameters of the patients like age, weight, height, type of surgery and gender in the study were comparable with a $p$ value of $>$ 0.05 .

The sensory block in terms of highest sensory level achieved in group D 6(4-8) and in groupF was $8(6-10)(p<0.005)$, time of two segment regression in group D110.33 $\pm 11.544 \mathrm{~min}$ and group $F \quad 81.50 \pm 15.6 \mathrm{~min}(\mathrm{p}<0.001)$, time of regression to $\mathrm{S}_{1}$ segment group

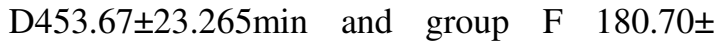
$18.235 \mathrm{~min} \quad(\mathrm{p}<0.001) \quad$ were statistically significant but time required to achieve the highest sensory level in group D was $6.37 \pm 1.06$ and in group $\mathrm{F}$ was $6.52 \pm 1.90 \mathrm{~min}$ was comparable, which was not statistically significant $(\mathrm{p}>0.05)$.

The degree of motor block achieved in terms of time required for Bromage 3 in group $D$ was5.71 $\pm 1.369 \mathrm{~min}$ and in group $\mathrm{F}$ was5.41 $\pm 1.69 \mathrm{~min}$ which was not statistically significant buttime required for regression to Bromage 0 in group D was $407.53 \pm 18.91 \mathrm{~min}$ and in group $F$ was $149.37 \pm 12$ min which was statistically significant. $(\mathrm{p}<0.001)$

Ramsay sedation score in both the groups was 3 which were not significant. (Table 1)

Side effects like vomiting, nausea, bradycardia, hypotension, pruritis and shivering were not statistically significant compared between the groups. 
Intrathecal dexmedetomidine and fentanyl with bupivacaine did not have much effect on vital parameters except for the decrease in heart rate in dexmedetomidine group which was significant. (Figure 1 and 2)

\begin{tabular}{|l|l|l|l|}
\hline Characteristics & Group D & Group F & Remarks \\
\hline Age (years) & $34.93 \pm 9.5$ & $34.93 \pm 9.5$ & $>0.05$ \\
\hline $\begin{array}{l}\text { Sex } \\
\text { Female }\end{array}$ & 16 & 13 & $>0.05$ \\
\hline Height (centimetres) & 14 & 17 & \\
\hline Weight (kilograms) & $165.1 \pm 7.23$ & $156 \pm 11.1$ & $>0.05$ \\
\hline Time for Highest Sensory level & $6.37 \pm 1.06$ & $6.52 \pm 1.90$ & $>0.05$ \\
\hline $\begin{array}{l}\text { Highest Sensory Level } \\
\text { Achieved }\end{array}$ & $6(4-8)$ & $8(6-10)$ & $<0.05$ \\
\hline $\begin{array}{l}\text { Time of two segments } \\
\text { regression }\end{array}$ & $110.33 \pm 11.54$ & $81.50 \pm 15.6$ & $<0.001$ \\
\hline $\begin{array}{l}\text { Time of sensory regression to } \\
\text { S1 }\end{array}$ & $453.67 \pm 23.26$ & $180.70 \pm 18$ & $<0.05$ \\
\hline Onset of Bromage 3 & $5.71 \pm 1.369$ & $5.41 \pm 1.69$ & $>0.05$ \\
\hline Regression to Bromage 0 & $407.53 \pm 18.91$ & $149.37 \pm 12$. & $<0.05$ \\
\hline Time to rescue analgesia & $231.93 \pm 17.83$ & $160.13 \pm 15$ & $<0.001$ \\
\hline $\begin{array}{l}\text { Sedation score } \\
\text { Bradycardia } \\
\text { Pruritis }\end{array}$ & 3 & $39 \pm 6.9$ & $>0.05$ \\
\hline $\begin{array}{l}\text { Shivering } \\
\text { Vompliting }\end{array}$ & 1 & 2 & $>0.05$ \\
\hline Figations & 9 & 2 & $>0.05$ \\
\hline & 0 & 3 & $>0.05$ \\
\hline & & 3 & $>0.05$ \\
\hline
\end{tabular}

Figure1: Heart rate changes from baseline upto 120 minutes in both groups.

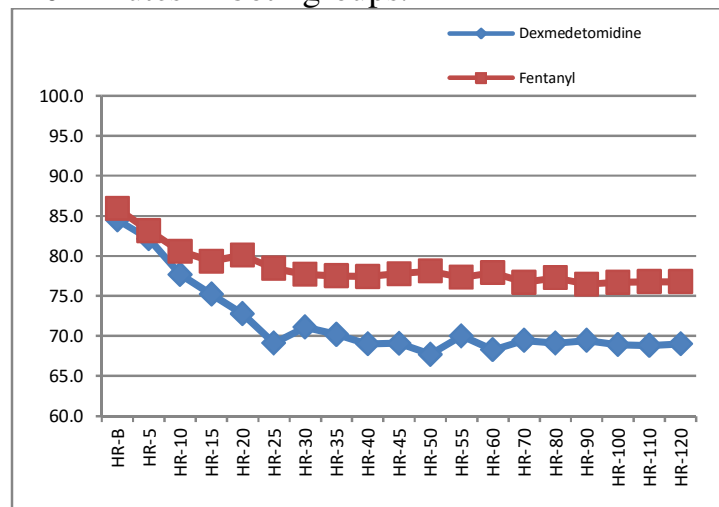

Figure 2: Mean Arterial Blood pressure changes in both groups

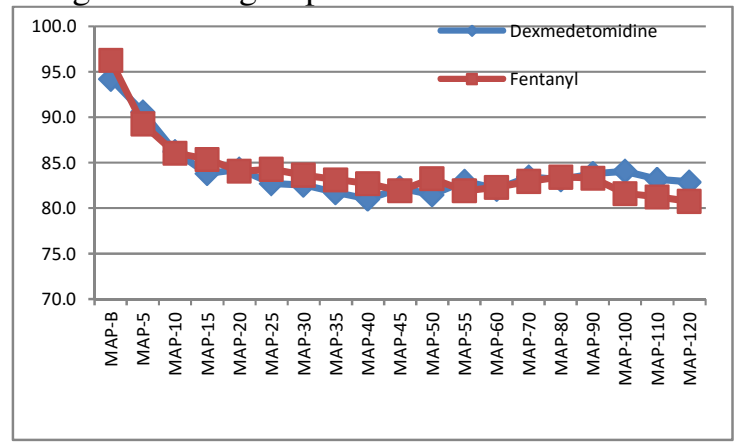

\section{Discussion}

Neuraxial opioids provide good analgesia similar to systemic administration, but in small doses and concentrations with less risk of systemic side effects. Intrathecal opioids exert its effect by combining with opioid receptors in the dorsal horn of spinal cord and may have supraspinal spread and action. Fentanyl being lipophilic and more potent, addition of small doses to spinal anaesthesia can produce more rapid onset and better quality surgical block and lead to more rapid recovery of motor function and allow for earlier discharge after surgery ${ }^{1,2}$.

Alpha 2 adrenergic receptor agonists like clonidine and dexmedetomidine have been the focus of interest for their sedative, analgesic, sympatholytic and haemodynamic stabilizing properties. Clonidine has been studied extensively than dexmedetomidine. Clonidine has been used intrathecally to prolong the sensory and motor block and reduce tourniquet pain. It prolongs and intensifies the effect of spinal anaesthetic by altering systemic absorption. Dexmedetomidine is a newer, highly selective drug in the same family, with a different more favourable pharmacokinetic profile. The analgesic property of dexmedetomidine is $8-10$ folds more than clonidine. It has been recently used as a systemic analgesic and regional anaesthetic adjuvant both intrathecal and epidural to intensify and prolong the action of analgesics and local anaesthetics ${ }^{3-5}$.

In the present study the highest mean sensory block, the mean time taken for two segment regression and the mean time taken for regression to $S_{1}$ segment was statistically significant with $\mathrm{p}$ value of $<0.001$ in group $\mathrm{D}$ in comparison to group F.Gupta et $\mathrm{al}^{6}$ whocompared 5ug dexmedetomidine and 25 ug of fentanyl with bupivacaine intrathecally found significant change in dexmedetomidine group with regard to time taken for two segment regression and time taken for regression to $\mathrm{S} 1$ segment.Fyneface-Ogan et $\mathrm{al}^{7}$ used dexmedetomidine $2.5 \mathrm{ug}$ intrathecally found significant change in time to achieve highest sensory block and time taken for regression to S1when compared to fentanyl. Similar results were found in the study of Madhyet $\mathrm{al}^{8}$. The variations in the results may be due to varying doses (volume and concentration) of bupivacaine, fentanyl and dexmedetomidine used. 
The mean time taken for onset of Bromage 3 in group $\mathrm{D}$ and group $\mathrm{F}$ were comparable. The mean time taken for regression to Bromage 0 in group D was statistically significant with a $p$ value of $<0.001$. Similar results were found in the study of Gupta et $\mathrm{al}^{1}$ and Al-Ghanem et $\mathrm{al}^{5}$. Al Mustafa et $\mathrm{al}^{9}$ who used varying doses of dexmedetomidine found statistically significant change in the onset of Bromage 3 and regression to Bromage 0.

The duration of analgesia is prolonged in dexmedetomidine group when compared to fentanyl. The mean time for rescue analgesia was significantly higher with dexmedetomidine. There is a wide variation in time for first rescue analgesia in dexmedetomidine and fentanyl groups in various studies of Gupta et $\mathrm{al}^{6}$, Eid et $\mathrm{al}^{10}$ and Jamliya et $\mathrm{al}^{11}$. But dexmedetomidine produced prolonged analgesia when compared to fentanyl which was statistically significant in all the studies.

Intrathecal dexmedetomidine and fentanyl with bupivacaine did not have much effect on vital parameters except for the decrease in heart rate in dexmedetomidine group which was significant $(p<0.05)$. Similar observation was made by Mohammed et $\mathrm{al}^{12}$. It may be due to sympatholytic effect of dexmedetomidine.Gupta et $\mathrm{al}^{6}$, Al-Mustafa et $\mathrm{al}^{9}$ and Tarbeeh et $\mathrm{al}^{13}$ did not find much change between the groups.

The patients in both the groups had a sedation score of 2 or 3 , which is not statistically significant with a $p$ value of $>0.05$. This may be attributed to the sedative effects of both the drugs.

The side effects like nausea, vomiting, hypotension, decrease in saturation, pruritis and shivering during intraoperative and postoperative period were comparable $(\mathrm{p}>0.05)$. Similar observations were noted in Wahlander et $\mathrm{al}^{14}$ Gupta et $\mathrm{al}^{15}$, Ogan et $\mathrm{al}^{7}$, Bajwa et $\mathrm{al}^{16}$ and El-Hennawy ${ }^{17}$.

\section{Conclusion}

In our study comparing intrathecal dexmedetomidine and intrathecal fentanyl with bupivacaine, the results indicate that dexmedetomidine provides better sensory blockade in terms of highest sensory level achieved, time of two segments regression and time of regression to $S_{1}$ segment and prolonged motor blockade when compared to fentanyl. The hemodynamic stability and side effects were similar in both the groups.

We conclude that dexmedetomidine may find a place in regular clinical use as an intrathecal adjuvant with hyperbaric bupivacaine due to its improved quality of sensory and motor block characteristics when compared to fentanyl. Hence dexmedetomidine may be used as an alternate to fentanyl for intrathecal use.

\section{References}

1. Gupta R, Bogra J, Verma R, Kohli M, Kushwaha JK, Kumar S. A Comparative study of intrathecal Dexmedetomidine and Fentanyl as adjuvants to Bupivacaine. J AnaesthClinPharmacol 2011;27(3):339-343. http://dx.doi.org/10.4103/0970-9185.83678 PMid:21897504 PMCid:PMC3161458

2. Brown LD. Spinal Anesthesia in Miller's anesthesia. Miller RD Editor. 7th edition Churchill Livingstone

Elsevier Philadelphia, 2010;2:1611-1638

3. Pitkanen M. Techniques of Neural Blockade in Clinical Anesthesia in Cousins and

Brindenbaugh's Neural

Blockade in Clinical Anesthesia and Pain Medicine. Cousins MJ Editor. 4th edition. Lippincott Williams and Wilkins China; 2009:216-217.

4. Al-Ghanem S, Massad I M, Al-Mustafa M M, Khaled R Al-Zaben, Ibrahim Y Qudaisat, Ayman M Qatawneh, Hamdi M Abu-Ali. Effect of adding Dexmedetomidine versus Fentanyl to intrathecal Bupivacaine on spinal block characteristics in gynecological procedures: A double blind controlled study. American Journal of Applied Sciences 2009;6(5):882-887. http://dx.doi.org/10.3844/ajassp.2009.882.887

5. Gupta R, Bogra J, Verma R, Kohli M, Kushwaha JK, Kumar S. Dexmedetomidine as an intrathecal adjuvant for postoperative analgesia. Indian J Anaesth 2011;55(4):347-351.

http://dx.doi.org/10.4103/0019-5049.84841 PMid:22013249 PMCid:PMC3190507

6. Fyneface - Ogan S, Job OG, Enyindah CE. Comparative effects of single shot intrathecal Bupivacaine with Dexmedetomidine and Bupivacaine with Fentanyl on labor outcome. ISRN Anesthesiology. 2012;2012:1-6. http://dx.doi.org/10.5402/2012/816984

7. Mahdy WR, Abdullah SI. Effect of adding dexmedetomidine versus fentanyl to intrathecal bupivacaine on spinal block characteristics and neonatal outcome in uncomplicated ceasarean delivery: A randomized double blind placebo 
controlled study. Menoufiya Medical Journal 2011:24(1);221-231.

8. Al-Mustafa M M, Abu-Halaweb S A, Aloweidi A S, Mursbidi M M, Ammari B A, Awawad Z M et al. Effect of Dexmedetomidine added to spinal Bupivacaine for urological procedures. Saudi Med J 2009;30(3):365-370.

PMid:19271064

9. Eid HEA, Shafie MA, Youssef H. Dose-related prolongation of hyperbaric Bupivacaine spinal anesthesia by Dexmedetomidine. Ain Shams Journal of Anesthesioloy. 2011;4(2):83-95.

10. Jamliya RH, Deshmukh V, Rajesh C, et al. Effect of Adding Dexmedetomidine In Intrathecal Bupivacaine Versus Intrathecal Bupivacaine Alone On Spinal Block Characteristics In Orthopaedic Lower Limb Procedures [A Comparative Study] RJPBCS January-March 2013; 4(1);1340-6.

11. Mohamed MA, Fares KM, Mohamed SA.

Efficacy of intrathecally administered dexmedetomidine versus dexmedetomidine with fentanyl in patients undergoing major abdominal cancer surgery. Pain physician 2012;15:339-348. PMid:22828688

12. Tarbeeh GA, Mohamed AA. Effects of intrathecal bupivacaine-fentanyl versus bupivacaine-dexmedetomidine in diabetic surgical patients. Egyptian Journal of Anaesthesia 2013;29:13-18. http://dx.doi.org/10.1016/j.egja.2012.08.008

13. Wahlander S, Frumento RF, Wagener G, et al. A prospective, double-blind, randomized, placebocontrolled

study of dexmedetomidine as an adjunct to epidural analgesia after thoracic surgery. Journal of Cardiothoracic and vascular Anesthesia, 2005;19(5):630-635. http://dx.doi.org/10.1053/j.jvca.2005.07.006 PMid:16202898

14. Gupta R, Bogra J, Verma R, et al. Dexmedetomidine as an intrathecal adjuvant for postoperative analgesia. Indian J Anaesth 2011;55:347-51 http://dx.doi.org/10.4103/0019-5049.84841 PMid:22013249 PMCid:PMC3190507

15. Bajwa SJS, Arora V, Kaur J, et al. Comparative evaluation of dexmedetomidine and fentanyl for epidural analgesia in lower limb orthopedic surgeries. Saudi Journal of Anaesthesia; Octoberdecember 2011;5(4):365-370.

http://dx.doi.org/10.4103/1658-354X.87264

PMid:22144922 PMCid:PMC3227304

16. El-Hennawy AM, Abd-Elwahah AM, Abd -

Elmaksoud AM, El-Ozairy $\mathrm{H}$ S, Boulis S. Addition of clonidine or dexmedetomidine to bupivacaine prolongs caudal analgesia in children. $\mathrm{Br}$ J Anaesth 2009;103:268-74. http://dx.doi.org/10.1093/bja/aep159

PMid:19541679 